Institute of $\mathbf{F}_{\text {ood and }} \mathbf{A}$ gricultural $\mathbf{S}_{\text {ciences }}$

\title{
2002 Cotton Defoliation and Harvest Aid Guide ${ }^{1}$
}

\section{L. Wright and B. J. Brecke ${ }^{2}$}

Cotton requires about 155 days of growth from planting to harvest in Florida. Important management decisions have to be made throughout the growing season, and decisions about defoliation and boll opening can affect quality and storage time if the crop is put into modules. Stain from poorly defoliated plants or regrowth and moisture from the green tissue cause the greatest loss in quality.

There are several ways to determine when to defoliate cotton. An old rule of thumb is to defoliate when $60 \%$ of the bolls are open. Another method is nodes above cracked bolls (NACB). Research has shown that cotton with four nodes above the highest cracked boll can be defoliated without significant weight or quality loss. If NACB counts average five or more, defoliant applications should be delayed.

Experience with harvest aids (boll openers, regrowth retardants, dessicants, and mature and juvenile foliage removal) has shown that timing of the defoliant should be based on yield potential and quality of the mature unopened bolls while considering the potential yield and fiber loss of the bolls which are already open. The largest bolls are generally those set early and low nearest the main stem on the plant. Where fruiting was hindered by early insect damage, it may be desirable to wait as long as possible to allow the top crop to develop and the $60 \%$ rule may not apply. A crop that set and retained most of the early fruit may be ready for defoliation at $50 \%$ open bolls. Also, where large acreage has to be harvested, growers may sacrifice some of the more immature bolls that contribute little to the final yield so that harvest can begin before adverse weather conditions reduce overall yield and quality of the crop. Bolls set in mid-summer are usually larger and mature in 40 to 50 days, while the bolls set in August can take 60 days or longer to mature and often contribute little to final yield if the crop had a normal fruiting season. Those late flowers look attractive and may give the appearance of adding to the final yield of the crop, but should not be given preference over the fruit that was set during the first 3 to 4 weeks of bloom. It has been shown many times that the fruit set during the first 4 weeks of bloom normally contributes 90 to $95 \%$ of the total yield of the cotton crop.

Estimating the number of mature, open bolls in the field is helpful in scheduling the defoliant and boll opener. Ten mature bolls per foot of row will produce a bale of cotton under good growing conditions. More bolls will be needed if they are higher on the

1. This document is SS-AGR-181, one of a series of the Agronomy Department, Florida Cooperative Extension Service, Institute of Food and Agricultural Sciences, University of Florida. First published September 2002. Visit the EDIS Web Site at http://edis.ifas.ufl.edu.

2. D. L. Wright, professor, North Florida Research and Education Center, and B. J. Brecke, professor, West Florida Research and Education Center, Cooperative Extension Service, Institute of Food and Agricultural Sciences, University of Florida, Gainesville, 32611.

The use of trade names in this publication is solely for the purpose of providing specific information. UF/IFAS does not guarantee or warranty the products named, and references to them in this publication does not signify our approval to the exclusion of other products of suitable composition.

The Institute of Food and Agricultural Sciences is an equal opportunity/affirmative action employer authorized to provide research, educational information and other services only to individuals and institutions that function without regard to race, color, sex, age, handicap, or national origin. For information on obtaining other extension publications, contact your county Cooperative Extension Service office. Florida Cooperative Extension Service/Institute of Food and Agricultural Sciences/University of Florida/Christine Taylor Waddill, Dean. 
plant and less if they are lower on the plant. Counts should include (1) open bolls, including cracked bolls; (2) green bolls that are mature and string out when cut with a knife; (3) immature bolls that are harvestable or will mature while conditions are favorable.

The crop should be defoliated in stages where large acreages are to be harvested. Harvest aids should be applied approximately 12 to 14 days ahead of picking. A four-row picker can pick about 40 acres a day in the early part of the season but will pick less later in the season due to shorter days.

There are different ways to defoliate cotton, and several harvest aid chemicals are available that work well in Florida. The choice depends on whether the cotton has normal growth, is rank or has weed overgrowth, and the time of year. With rank cotton and cotton that has weed overgrowth, it is usually best to use a normal rate of defoliant and then to come back with a second application to defoliate the bottom of the crop. Higher rates of defoliants may kill the plant and cause the leaves to stay attached instead of allowing the crop to mature and form the abscission layer, resulting in leaf drop.

Drought stress and cool weather can make plants more difficult to defoliate, especially where high levels of nitrogen remain in the plant. High residual nitrogen in the soil and in the plant can result in regrowth as soon as moisture is available. The young green leaves that appear in the terminal can stain the lint during the picking process. As the weather cools later in the season, harvest aids are less active. Harvest aids should be applied three or four days after a cool snap.

Defoliants work in one of two ways; by herbicidal action or by hormonal activity. Folex, Def, and Harvade are examples of herbicidal defoliants that injure plant leaves. The plant responds by producing ethylene, which causes the formation of the abscission layer at the base of the leaf petiole. High rates of these materials kill the plants, slowing or preventing leaf drop, thus causing more trash in the lint during the picking operation. Dropp, Prep, Super Boll, and ethephon are hormonal defoliants. The ethephon products actually release ethylene which stimulates further ethylene production in the bolls and leaves. Dropp is an example of a growth hormone called cytokinin which promotes ethylene production in cotton. These materials are compatible in tank mixes, which aids the defoliation process. Under cool conditions, use of petroleum-based crop oils has been shown to improve performance. Use of crop oils under high temperatures may result in leaf sticking because plants are killed before the abscission layer has formed.

There is no best harvest aid material that will defoliate, stimulate boll opening, prevent regrowth, and perform equally well under hot or cool and dry or moist conditions. Combinations of products can result in good performance under a broad range of conditions that normally occur in Florida. All of the harvest aid chemicals have a significant reduction in activity at 60-65 degrees. Of all the defoliants, Dropp is the most temperature dependent, while the least temperature dependent chemicals are Harvade, Def 6 or Folex, which provide adequate activity at temperatures of 55 degrees. Ethephon (Prep, Superboll, Ethephon) is intermediate in activity at cool temperatures.

A cotton crop that is mature and has little new growth at defoliation can be easily defoliated with any material, while those fields that have green actively growing leaves and are still blooming due to excess fertility and moisture can be more difficult to defoliate, and regrowth may occur. Regrowth suppression is usually accomplished with Dropp as long as temperatures are above 60 to 65 degrees. If temperatures drop below this range, glyphosate products may be the best choice for regrowth suppression on non-Roundup Ready cotton. Glyphosate in combinations with Def has been shown to do a satisfactory job of defoliating, cotton as well as Dropp and Def combinations, with no more and, in some cases, less desiccation.

Gramoxone Max/Boa (paraquat) will desiccate regrowth to prevent staining of the lint and heat problems in the modules. However, paraquat can freeze unopened bolls, so all mature bolls should be open before use of this material. Generally, trash from desiccation can be removed in the ginning process, while stains cannot. 
Perhaps the most important factor to consider in timing of defoliants is whether unopened bolls are harvestable. Mature bolls will be too hard to dent when squeezed with your hand, and cannot be easily cut with a knife. Lint will also string out when the boll is sliced and seed coats will be yellow to tan in color. Bolls set late in the season where moisture and nitrogen are adequate or excessive should not overly influence the decision to apply harvest aids due to potential loss of large mature bolls at the bottom of the plant. Late, top bolls are often small and may be damaged by frost and may contribute little to yield.

\section{Cotton Defoliation/Harvest Aid Suggestions}

The following recommendations are guidelines for harvest aid application. Specific rates should be adjusted according to temperature, humidity, day-length, plant leaf condition and maturity, expected weather and desired effects such as defoliation, regrowth control, boll opening and/or weed control. Defoliants should be applied in a minimum spray volume of $5 \mathrm{gal} / \mathrm{A}$ by air and 10 gal/A by ground. Fields should fit into one of the following categories based on temperature and crop conditions.

I - EARLY SEASON (high $90^{\circ} \mathrm{F}$ plus, lows $70^{\circ} \mathrm{F}$ plus)

\section{DEFOLIATION Only}

1. DEF/Folex@1.5 to $1.75 \mathrm{pt}$ (reduce to $1.25 \mathrm{pt}$ if above $94^{\circ} \mathrm{F}$

2. Aim @ 0.67 oz + crop oil @ 1\% v/v (trial basis)

3. Harvade @ 8oz + 1 pt crop oil

4. Finish6@11 oz+DEF/Folex @3 to 6 oz

5. Sodium Chlorate @ 3 lb (mature foliage only; do not mix with $\mathrm{DEF} /$ Folex or ethephon)

\section{DEFOLIATION AND REGROWTH} CONTROL

6. Dropp/Free Fall 50W @ 0.2 lb (for maximum regrowth control)
7. Dropp/Free Fall 50W @ 0.1 lb (for minimum regrowth control)+DEF/Folex @ $1 \mathrm{pt}$

8. Dropp/Free Fall 50W @ 0.125 lb (for good regrowth control) DEF/Folex @ 8 to $12 \mathrm{oz}$

9. Dropp/Free Fall 50W @ 0.15 lb (for superior regrowth control) DEF/Folex @ 4 to $6 \mathrm{oz}$

10. Dropp/Free Fall 50W @ 0.1 to $0.15 \mathrm{lb}+$ Harvade@ 8 oz + 1 pt crop oil

11. Leafless@10 oz+1 pt crop oil

12. Ginstar@6.4 to 8 oz.

13. glyphosate@1.2 to 2 pt + (one of the following)

-DEF/Folex @ 1 pt or

- Harvade @8 oz+1 pt crop oil

\section{DEFOLIATION AND BOLL OPENING}

14. ethephon@ 2.0 to $2.67 \mathrm{pt}$

15. ethephon@ @ 1.33 to $1.5 \mathrm{pt}+$ (one of the following)

- DEF/Folex @ 1 to 1.25 pt or

- Dropp/Free Fall 50W @ 0.1 lb or

- Ginstar @ 4 to 6 oz or

- Harvade @ $8 \mathrm{oz}+1$ pt crop oil or

- Aim EC @ 1 oz + crop oil @ 1\% v/v

16. Cotton Quik@1.75 to 2 qt + (one of the following)

-DEF/Folex @ 4 to 6 oz or

- Dropp/Free Fall 50W @ 0.1 lb or

- Ginstar @ 4 to 6 oz or

- Harvade @ 8 oz + 1 pt crop oil or

- Aim EC @ 1 oz

17. Finish $6 @ 1.33 \mathrm{pt}+$ (one of the following) 
-DEF/Folex @ 4 to 6 oz or

- Dropp/Free Fall 50W @ 0.1 lb or

- Ginstar@ 4 to 6 oz or

- Harvade @ 8 oz + 1 pt crop oil or

-Aim EC@ 1 oz + crop oil @ 1\% v/v

DEFOLIATION , BOLL OPENING AND REGROWTH CONTROL

18. ethephon@1.33 to $1.5 \mathrm{pt}+$ (one of the following)

- Dropp/Free Fall @ 0.1 to 0.125 lb + DEF/Folex @ 4 to 6 oz or

- Dropp/Free Fall 50W @0.125 lb or

- Leafless @ 10 oz or

- Ginstar@6.4 oz

19. Cotton Quik @ 1.75 to $2 \mathrm{qt}+$ (one of the following)

- Dropp/Free Fall 50W @ 0.1 to 0.125 lb or

- Leafless @ 10 oz or

- Ginstar@6.4 oz

20. Finish $6 @ 1.33 \mathrm{pt}+$ (one of the following)

- Dropp/Free Fall 50W @ 0.1 to 0.125 lb or

- Leafless @10 oz or

- Ginstar @ 6.4

II - MID SEASON (highs 80 to $89^{\circ} \mathrm{F}$ plus, lows 60 to $70^{\circ} \mathrm{F}$ )

DEFOLIATION Only

1. DEF/Folex @ 1.5 to $1.75 \mathrm{pt}$

2. Aim EC @ 1 oz + crop oil @ 1\% v/v

3. Harvade @ $8 \mathrm{oz}+1 \mathrm{pt}$ crop oil

4. Finish $6 @ 11$ oz+DEF/Folex @6 to 8 oz
5. Sodium Chlorate @ 4 lb (mature foliage only; do not mix with DEF/Folex or ethephon)

\section{DEFOLIATION AND REGROWTH CONTROL}

6. Dropp/Free Fall 50W @ 0.2 lb

7. Dropp/Free Fall $50 \mathrm{~W} @ 0.125$ to 0.14 lb + (one of the following)

-DEF/Folex @ 1 pt or

-Harvade @ 8 oz + 1 pt crop oil

8. Leafless @ 10 to 12 oz +1 pt crop oil

9. Ginstar@6.4 to 8 oz

10. glyphosate@ 1.2 to $2 \mathrm{pt}+$ (one of the following)

- DEF/Folex @ 1 pt or

- Harvade @ 8 oz + 1 pt crop oil

\section{DEFOLIATION AND BOLL OPENING}

11. ethephon@2 to 2.67 pt

12. ethephon@ 1.5 to $2 \mathrm{pt}+$ (one of the following)

- DEF/Folex @ 1 to 1.25 pt or

- Dropp/Free Fall 50W @ 0.1 lb or

- Ginstar @6.4 oz or

- Harvade @ 8 oz + 1 pt crop oil or

- Aim EC @ 1 oz + crop oil @ 1\% v/v

13. Cotton Quik@ 2 qt + (one of the following)

-DEF/Folex@8 to 12 oz or

- Dropp/Free Fall 50W @ 0.1 lb or

- Ginstar @6.4 oz or

- Harvade @ 8 oz + 1 pt crop oil or

- Aim EC@ 1 oz 
14. Finish $6 @ 1.33$ to $1.5 \mathrm{pt}+$ (one of the following)

-DEF/Folex @ 8 to 12 oz or

- Dropp/Free Fall 50W @ 0.1 lb or

- Ginstar@6.4 oz or

- Harvade @ 8 oz + 1 pt crop oil or

-Aim EC @ 1 oz + crop oil @ 1\% v/v

DEFOLIATION, BOLL OPENING, AND REGROWTH CONTROL

15. ethephon@1.5 to $2 \mathrm{pt}+$ (one of the following)

- Dropp/Free Fall @ 0.125 to 0.14 lb + DEF/Folex@8 to 10 oz or

- Dropp/Free Fall 50W @ 0.125 to 0.16 lb or

- Leafless @ 10 to 12 oz

16. Cotton Quik @ $2.0 \mathrm{qt}+$ (one of the following)

- Dropp/Free Fall 50W @ 0.125 to 0.14 lb or

-Leafless@ 10 to $12 \mathrm{oz}$

17. Finish $6 @ 1.33$ to $1.5 \mathrm{pt}+$ (one of the following)

- Dropp/Free Fall 50W @ 0.125 to 0.14 lb or

-Leafless@10 to $12 \mathrm{oz}$

III - LATE SEASON (highs below $80^{\circ} \mathrm{F}$, lows below $60^{\circ} \mathrm{F}$ ) NOTE: Under these conditions, cotton should often be preconditioned and then defoliated (see Section IV) or routinely defoliated with combinations, which include ethephon.

DEFOLIATION only

1. DEF/Folex@1.5 to $2 \mathrm{pt}+$ Gramoxone Max/Boa@ 4 to 6 oz

2. Harvade @ $8 \mathrm{oz}+1$ pt crop oil
3. Ginstar@8 to 10 oz

4. Finish $6 @ 11$ oz to 16 oz + DEF/Folex @6 to $12 \mathrm{oz}$

5. Aim EC @ 1 oz + crop oil @ 1\% v/v

6. Sodium Chlorate@ @ lb

\section{DEFOLIATION AND BOLL OPENING}

7. ethephon@2 to $2.67 \mathrm{pt}$

8. ethephon@1.5 to $2.67 \mathrm{pt}+$ (one of the following)

- DEF/Folex @ 1.25 to 2 pt or

- Ginstar @ 8 to 10 oz or

- Harvade @ 8 oz + 1 pt crop oil or

- Aim EC @ 1 oz + crop oil @ 1\% v/v

9. Cotton Quik@ 2 qt + (one of the following)

- DEF/Folex @ 1 to 1.5 pt or

- Ginstar@ 8 to 10 oz or

- Harvade@8 oz + 1 pt crop oil or

- Aim EC@ @ oz

10. Finish $6 @ 1.5 \mathrm{pt}+$ (one of the following)

-DEF/Folex @ 1 to 1.5 pt or

- Ginstar@ 8 to 10 oz or

- Harvade@8 oz + 1 pt crop oil or

- Aim EC @ $1 \mathrm{oz}+$ crop @ 1\% v/v

IV - PRECONDITIONING: Fields with dense canopy of foliage and significant numbers of green bolls may require two applications. The goal is to remove much of the foliage with an initial application, exposing unopened bolls. The follow-up application should be made 7 to 10 days later when sufficient leaf drop has occurred to allow spray coverage of bolls with ethephon, Cotton Quik, or Finish. 
Initial Preconditioning Treatment

1. DEF/Folex@ 0.5 to $1.25 \mathrm{pt}$

2. ethephon@0.67 to 1.33 pt

3. glyphosate@1.2 to 2 pt

Follow-up Treatments

Should include Boll Openers with harvest aid mixtures listed in Sections I, II, and III.

\section{General Notes:}

Beware of off-target movement of harvest aid products, especially when aerial applications. Significant problems have been observed with mixtures that include glyphosate, paraquat, or Aim.

Dropp/Free Fall 50W is sensitive to wash-off if rain occurs within 6 hours of application; addition of DEF/Folex improves rain-fastness. Ammonium sulfate@ 2 lb/A often improves activity of Drop/Free Fall 50W and Harvade. DEF/Folex plus Dropp/Free Fall 50W combinations have a tendency to cause "leaf sticking" when temperatures exceed $94^{\circ} \mathrm{F}$, in combinations with spray adjuvants, or rates are too high. Consider reducing rates by 10 to $20 \%$ when temperatures exceed $94^{\circ} \mathrm{F}$. Regrowth control is minimal with Dropp/Free Fall 50W rates below 0.1 lb/A or Ginstar rates below $6.4 \mathrm{oz}$. Ginstar includes the same active ingredients as in Dropp and diuron. Leafless includes the active ingredients in Dropp and Harvade.

Roundup or generic glyphosate products will NOT provide regrowth suppression on RR cotton. Adding spray adjuvant may enhance activity of treatments when temperatures are low. However, adjuvants may sometimes cause "leaf sticking," and thus, these products should be used with caution early in the season.

Addition of Gramoxone Max/Boa @ 1 to 4 oz may aid defoliation and weed desiccation with standard harvest aid mixtures. Off-target movement may cause injury to sensitive plants such as pine trees.

Leaf All may serve as a replacement for $\mathrm{DEF} /$ Folex in combinations on a one-for-one rate basis.
Accelerate may be used as a tank-mix with either DEF/Folex or sodium chlorate to hasten leaf drop by approximately 2 to 3 days.

\section{V - HARVEST AID WEED MANAGEMENT}

1. Gramoxone Max/Boa @ 1 to 4 oz in combination with standard defoliant mixtures.

Use lowest rate during warm temperatures. Avoid off-target drift, especially to pines.

2. Roundup @ 1.5 to 2 pt in combination with DEF/Folex, Harvade, and/or ethephon.

Roundup provides fair suppression of cotton regrowth. Avoid off-target drift.

3. Harvade @ 8 oz + crop oil 1 pt. Effective on mature weeds including morningglory, sicklepod, tropic croton, and Florida beggarweed.

4. Aim@0.67 oz + crop oil @ 1\% v/v. Effective on morningglory, and coffee senna.

5. a) Defoliate, then b) Dessiccate with Gramoxone Max/Boa as listed below. 
Table 1. Dessicants for Cotton Harvest Preparation

\begin{tabular}{|c|c|c|c|c|}
\hline \multirow[t]{2}{*}{ Dessicate } & \multirow[t]{2}{*}{$\mathrm{lb}$ Al/gal } & \multirow{2}{*}{$\begin{array}{c}\text { Formulation } \\
\text { Rate/Acre }\end{array}$} & \multicolumn{2}{|c|}{ Spray Volume, gal/A } \\
\hline & & & Ground & Air \\
\hline $\begin{array}{c}\text { Gramoxone } \\
\text { Max/Boa }\end{array}$ & $3.0 / 2.5$ & $\begin{array}{c}1 \text { to } 4 \mathrm{oz}^{1} \\
5.5 \mathrm{oz} \text { to } 1.5 \mathrm{pt}^{2}\end{array}$ & 10 to 20 & 5 \\
\hline Sodium Chlorate & 4 to 6 & 3 to $6 \mathrm{lb} \mathrm{Al}$ & 15 to 30 & 5 to 10 \\
\hline
\end{tabular}

${ }^{1}$ For addition to defoliant mixtures in cotton at least $75 \%$ open. Improves activity in colder, late season conditions. May cause crop dessication $\left(90^{\circ} \mathrm{F}\right.$ and above) and damage to immature bolls.

${ }^{2}$ For dessication of weeds and cotton regrowth after defoliation. Rates of 8 to $16 \mathrm{oz}$ are usually sufficient. Add surfactant at 1 to 2 qts/100 gals spray solution. Be prepared to harvest in a timely manner to minimize bark problems.

Table 2. Performance Rating of Harvest Aids by Function

\begin{tabular}{|c|c|c|c|c|c|}
\hline \multicolumn{6}{|c|}{ Function } \\
\hline Product & $\begin{array}{l}\text { Remove } \\
\text { Mature } \\
\text { Foliage }\end{array}$ & $\begin{array}{l}\text { Remove } \\
\text { Juvenile Foliage }\end{array}$ & Open Bolls & $\begin{array}{l}\text { Suppress } \\
\text { Regrowth }\end{array}$ & Dessicate Weeds ${ }^{2}$ \\
\hline Aim & $\mathrm{G}$ & G-E & $P$ & $P$ & $F$ \\
\hline DEF/Folex & G-E & $\mathrm{P}-\mathrm{F}$ & $P$ & $P$ & $P$ \\
\hline Dropp/Free Fall & G-E & G & $P$ & G-E & $P$ \\
\hline Ginstar & G-E & G & $P$ & G-E & $P$ \\
\hline Harvade & G-E & $P$ & $P$ & $P$ & $F-G$ \\
\hline Ethephon ${ }^{1}$ & $F-G$ & P-F & $E$ & $P$ & $P$ \\
\hline Sodium Chlorate & $\mathrm{F}$ & $P$ & $P$ & $P$ & $F-G$ \\
\hline Roundup & $P$ & $F$ & $P$ & $F-G$ & $G$ \\
\hline $\begin{array}{l}\text { Gramoxone } \\
\text { Max/Boa }\end{array}$ & $\mathrm{F}$ & $\mathrm{F}$ & $F$ & $P$ & $G$ \\
\hline Cotton Quik & $G$ & P-F & $\mathrm{E}+$ & $P$ & $\mathrm{~F}$ \\
\hline Finish & $G-E$ & $\mathrm{P}-\mathrm{F}$ & $E+$ & $\mathrm{F}$ & $P$ \\
\hline \multicolumn{6}{|c|}{$P=$ poor, $F=$ fair, $G=g o o d, E=e x c e l l e n t$} \\
\hline \multicolumn{6}{|c|}{$\begin{array}{l}{ }^{1} \text { ethephon (Prep, Ethephon 6, Super Boll, Bolld, etc.) } \\
{ }^{2} \text { refers to weed defoliation plus dry down to reduce harvest interference, green stain, and moisture }\end{array}$} \\
\hline
\end{tabular}

